\title{
PENGARUH SERVICE RECOVERY TERHADAP TINGKAT KEPUASAN NASABAH DI BANK PANIN KCU PEMATANGSIANTAR
}

\author{
Nancy Florida Siagian ${ }^{1)}$, Henry Dunan Pardede ${ }^{2)}$ \\ Hengki Mangiring Parulian Simarmata ${ }^{3)}$ \\ ${ }^{1}$ Keuangan dan Perbankan, Politeknik Bisnis Indonesia \\ email: Siagiannancyflorida@gmail.com \\ ${ }^{2}$ Keuangan dan Perbankan, Politeknik Bisnis Indonesia \\ email: henry.dunanpardede@yahoo.co.id \\ ${ }^{3}$ Manajemen Administrasi Perkantoran, Politeknik Bisnis Indonesia \\ email: hengkisimarmata.mm@gmail.com
}

\begin{abstract}
Service is very important factor in the service industry. Improving service quality can retain consumers and increase satisfaction. This study aims to examine and explain the magnitude of the effect of service recovery on customer satisfaction levels. The object of this research is Panin Bank KCU Pematangsiantar. This research is a quantitative study with a sample size of 97 customers using a purposive side. The collecting data method is using a questionnaire. The analysis technique uses a simple linear regression analysis model. Data are testing for validity test, reliability test, normality test, and coefficient of determination test. The results of the SPSS test showed that there was an effect of service recovery of 58.8\% on satisfaction, and the remaining $41.7 \%$ influenced by other factors not examined in this study. The t-test shows that there is a signifikant positive effect on customer satisfaction. The results of this study are to provide information to management in making service improvement policies. For subsequent research, the research variables can be developed like service quality and customer relationship management.
\end{abstract}

Keywords : Service Recovery, Customer Satisfaction.

\section{PENDAHULUAN}

Bank dan lembaga keuangan lain memiliki peranan yang penting bagi perekonomian masyarakat. Bank dapat meningkatkan taraf hidup masyarakat dengan cara membantu masyarakat dibidang pemodalan dan memberikan pembelajaran dalam pengelolaan uang. Semakin tinggi persaingan usaha Bank baik antar Bank, antar Bank dan BPR maupun Bank dengan lembaga keuangan lain non Bank mendorong manajemen Bank melakukan perbaikan pelayanan. Pentingnya perbaikan pelayanan dan inovasi Bank memberikan kenyamanan dan sikap puas konsumen terhadap Bank.
Persaingan antar Bank maupun dengan lembaga keuangan non Bank dapat mengakibatkan turunnya nasabah Bank. Oleh karena itu Bank melakukan perhatian pada pelayanan Bank terutama pelayanan dibagian frontliner agar nasabah merasa nyaman. Dalam memberikan pelayanan yang terbaik sering kali Bank mengalami kegagalan. Kegagalan pelayanan dapat disebabkan karena kesalahan teknologi maupun sumber daya manusia yang bekerja di Bank. Oleh karena itu Bank perlu mengantisipasinya dengan mengendalikan kegagalan tersebut agar tidak berdampak besar terhadap kinerja Bank. Disamping itu semakin tingginya tuntutan 
nasabah terhadap kinerja Bank mengakibatkan manajemen Bank perlu melakukan pengelolaan keluhan. Salah satu hal yang dapat dilakukan untuk mengantisipasi kegagalan pelayanan dengan melakukan service recovery.

Salah satu Bank yang tengah mengalami persaingan bisnis di Pematangsiantar adalah Bank Panin KCU Pematangsiantar. Dari data yang diperoleh berdasarkan jumlah nasabah bahwa terdapat peningkatan jumlah nasabah yang tidak terlalu signifikan. Tabel 1.1 di bawah ini dijelaskan jumlah nasabah Bank Panin KCU Pematangsiantar.

Tabel.1.1 Jumlah Nasabah Bank KCU Pematangsiantar

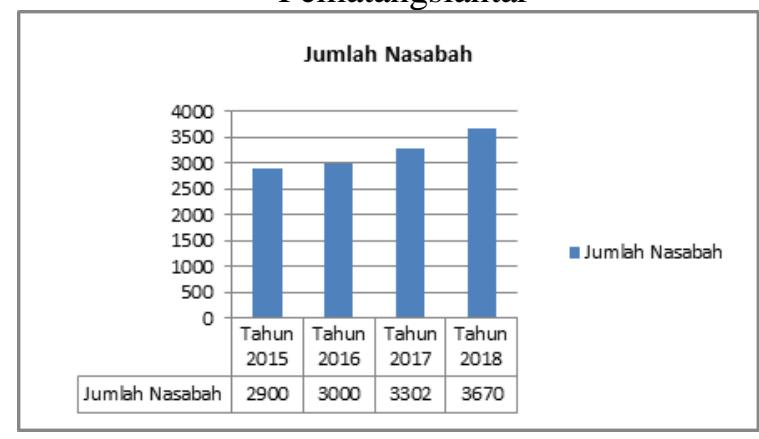

Dari data di atas dilihat bahwa jumlah pertambahan nasabah tidak terlalu signifikan dari tahun ke tahun dan tidak sesuai dengan target manajemen yang telah ditetapkan di atas 2\%. Dari tahun 2015 ke 2016 kenaikan sekitar $1.03 \%$, dari tahun 2016 ke 2017 kenaikan sekitar $1.1 \%$ dan tahun 2017 ke 2018 sekitar $1.11 \%$. Untuk memahami persoalan di atas maka pihak manajemen perlu melakukan evaluasi pelayanan yang diberikan. Manajemen melihat kembali tingkat complain nasabah terhadap pelayanan, seberapa banyak nasabah tidak melanjutkan jasa pelayanan lagi dan berpaling ke Bank lain. Dan bagaimana kualitas layanan yang diberikan karyawan terhadap nasabah selama proses kegiatan pelayanan Bank. Dari latar belakang penelitian di atas maka penulis tertarik untuk meneliti lebih jauh lagi tentang bagaimana service Recovery berpengaruh terhadap tingkat kepuasan nasabah pada Bank Panin KCU Pematangsiantar

\section{Rumusan Masalah}

Dalam penelitian ini rumusan masalah adalah berapa besar pengaruh service recovery terhadap tingkat kepuasan nasabah di Bank Panin KCU Pematangsiantar?

\section{Tujuan Penelitian}

Penelitian ini bertujuan untuk mengetahui besarnya pengaruh service recovery terhadap tingkat kepuasan nasabah di Bank Panin KCU Pematangsiantar

\section{Manfaat Penelitian}

Dalam penelitian ini terdapat dua manfaat yaitu:

1. Bagi Perusahaan, penelitian ini memberikan informasi dan cara pandang baru dalam menyelesaikan persoalan Bank dalam mengelola nasabahnya

2. Bagi dunia pendidikan, penelitian ini menambah wawasan tentang manajemen, pelayanan jasa khususnya topik perbankan.

\section{Tinjauan Pustaka}

\section{Service Recovery}

Pelayanan merupakan hal yang paling penting dalam industri jasa. Pelayanan yang baik akan meningkatkan konsumen baru, meningkatkan kepuasan, menjaga agar konsumen tetap loyal, memenangkan persaingan, meningkatkan jumlah pembelian, dan meningkatkan citra perusahaan [1]-[3]. Service recovery sebagai tindakan pemulihan yang diambil manajemen perusahaan karena adanya kegagalan pelayanan[4].

Service recovery merupakan tindakan yang diambil oleh manajemen agar pelanggan yang tidak puas terhadap pelayanan dapat kembali merasakan pelayanan dan menjadi puas. Services recovery menjadi evaluasi dan perbaikan demi keberlangsungan perusahaan[5].

Services recovery juga diartikan sebagai kebijakan dalam mengatasi kegagalan layanan yang mengakibatkan konsumen dapat dipertahankan. Service recovery dalam perusahaan jasa sangat penting karena menjadi komitmen manajemen untuk menyediakan pelayanan yang terbaik bagi konsumen dan siap melakukan perbaikanperbaikan. Services recovery memiliki fungsi (a) Mendeteksi kemungkinan muncul 
persoalan, (b) Memecahkan persoalan, (c) Mencegah terjadi kekecewaan, (d) Mengakomodasi keluhan [5] sedangkan menurut Liestyana tujuannya adalah (a) untuk mengendalikan kerugian waktu yang akan datang, (b) Menghilangkan ketidakpuasan, (c) Memperbaiki hubungan yang rusak dengan konsumen [6]. Service recovery akan memberikan pengertian kepada konsumen mengapa pelayanan terdahulu tidak memuaskan dan memberikan pengalaman baru dalam pelayanan berikutnya.

Service recovery adalah penekanan terhadap perbaikan dan solusi yang ditawarkan kepada konsumen agar konsumen tidak pindah ke pesaing [7], [8]

\section{Dimensi Service Recovery}

Penelitian Saputra dan Sunarti dimensi yang digunakan mengukur service recovery dengan Distributive justice, interactional justice dan procedural justice yang dijabarkan sebagai berikut meminta maaf dengan tulus, memberikan solusi yang cepat, memberikan respons yang cepat dan berempati, memberikan kemenangan kepada konsumen, melakukan perbaikan layanan, mengomunikasikan perbaikan.

Peneliti Liestyana menjelaskan dimensi yang digunakan untuk mengukur service recovery adalah tindakan koreksi, penjelasan, perlakuan khusus, permohonan maaf, pemberian kompensasi, menyampaikan keluhan konsumen keatasan dan tidak melakukan apapun [6].

Penelitian Tjitrokusumo dkk menjelaskan dimensi yang digunakan adalah (a) Distributive justice seperti kompensasi, ganti rugi atas kekecewaan, (b) Procedural Justice seperti proses penangan keluhan, keputusan tepat dari setiap keluhan, waktu yang tepat dalam mengatasi keluhan, dan bersikap fleksibel terhadap prosedur dalam penanganan keluhan. (c) Untuk interactive justice seperti penjelasan persoalan, pengakuan yang jujur atas kesalahan, sopan dan menghargai konsumen, berusaha maksimal mencari solusi dan memberikan sikap empati dan peduli [9].

Penelitian yang dilakukan Nursyamsiah dan Virgostin dimensi dalam service recovery adalah keadilan distributive, keadilan procedural, keadilan interaksional.

Pada penelitian ini dimensi yang digunakan untuk mengukur service recovery adalah Distributive justice yaitu atribut yang memfokuskan pada hasil dan penyelesaian service recovery, procedural justice yaitu keadilan yang diterima pelanggan, Interactional Justice yaitu keadilan yang dipersepsikan pelanggan.

\section{Kepuasan Nasabah}

Kepuasan merupakan penilaian dan sikap yang diberikan konsumen terhadap produk dan jasa untuk memenuhi kebutuhan dan keinginannya [7], [10]-[12].

Kepuasan diartikan sebagai perasaan bahagia, senang, sedih atas jasa yang diharapkan dengan yang diterima [13]. Ungkapan emosional tersebut dapat berupa kemarahan, kejengkelan, ketidakpuasan, netralitas, kesenangan, dan kegembiraan [14]. Kepuasan juga diartikan sebagai perasaan senang atau perasaan kecewa setelah membandingkan antara harapan dengan kinerja. Kepuasan dijelaskan sebagai evaluasi konsumen setelah melakukan pembelian. Faktor-faktor yang memengaruhi dari kepuasan dapat berupa (a) Harga, (b) Pelayanan, (c) Kualitas, (d) Merek, (e) Lokasi, (f) Desain [13].

\section{Dimensi Kepuasan Nasabah.}

Kepuasan nasabah dapat diukur dengan berbagai indikator seperti (a) Kualitas layanan, (b) Kualitas produk, (c) Harga, (d) Keadaan dan kondisi, (e) Faktor pribadi konsumen. Dalam penelitian Simarmata dan Saragih dimensi yang digunakan untuk mengukur kepuasan adalah (a) Kenyamanan yang dirasakan, (b) Kepuasan atas layanan, (c) keinginan untuk berbicara positif. Dalam penelitian Saputra dan Sunarti dimensi yang digunakan adalah (a) Kualitas produk, (b) Kualitas pelayanan, (c) Harga, (d) Emosi, dan (e) Biaya.

Pada penelitian ini dimensi yang digunakan untuk mengukur kepuasan adalah attribute related to product yaitu produk yang tersedia beragam dan tingkat suku bunga yang rendah, Attributes related to services yaitu 
pelayanan yang tuntas dan ada jalan keluar, attributes related to purchase yaitu informasi yang diberikan sangat akurat. .

\section{Hipotesis Penelitian}

Penelitian-penelitian

sebelumnya menunjukkan adanya pengaruh pelayanan pemulihan terhadap kepuasan seperti Penelitian Himmah menunjukkan adanya pengaruh positif signifikan dari variabel services recovery terhadap loyalitas pelanggan melalui kepuasan nasabah sebagai variabel intervening [14]. Penelitian Saputra dan Sunarti dimana terdapat pengaruh positif signifikan antara service recovery terhadap kepuasan pelanggan PDAM Kota malang [5], Simarmata dan Saragih dimana pelayanan memiliki pengaruh positif terhadap kepuasan masyarakat [13]. Berbeda dengan penelitian yang dilakukan oleh Tjitrokusumo dkk dimana distributive justice dan interactional justice berpengaruh positif sedangkan procedural justice berpengaruh negatif dan tidak signifikan.

Hipotesis penelitian ini adalah

- Ho : Tidak terdapat pengaruh Service recovery terhadap peningkatan kepuasan nasabah di Bank Panin KCU Pematangsiantar

- H1 : Terdapat pengaruh Service recovery terhadap peningkatan kepuasan nasabah di Bank Panin KCU Pematangsiantar

\section{METODE PENELITIAN}

\section{Jenis Penelitian}

Penelitian ini merupakan penelitian deskriptif dan kualitatif. Dimana penelitian secara deskriptif menggambarkan bagaimana service recovery digambarkan dalam pelayanan di Bank Panin KCU Pematangsiantar, sedangkan penelitian kualitatif bertujuan untuk mengetahui seberapa besar pengaruh dari variabel $\mathrm{X}$ terhadap variabel $\mathrm{Y}$ dalam penelitian.

\section{Lokasi Penelitian}

Penelitian dilakukan di Bank Panin KCU

Pematangsiantar.

Populasi dan Sampel
Populasi penelitian ini merupakan jumlah keseluruhan nasabah Bank Panin KCU Pematangsiantar sebanyak 3670 nasabah. Sampel yang digunakan dengan menggunakan rumus Slovin sebanyak 97 Nasabah dimana teknik pengambilan sampel dengan menggunakan nonprobabilitas sampling dengan metode purposive.

\section{Jenis dan Sumber Data}

Data dalam penelitian ini bersumber dari data primer dan data sekunder. Data primer diperoleh dengan penyebaran Kuesioner, Observasi, dan Dokumentasi. Kuesioner disebarkan kepada nasabah Bank Panin KCU Pematangsiantar, Oservasi dilakukan dengan berkunjung ke Bank dan melakukan pengamatan proses pelayanan di Bank dan Dokumentasi dilakukan dengan mendapatkan data-data penting yang berhubungan dengan penelitian. Data sekunder diperoleh dengan cara studi pustaka dari buku manajemen, jurnal nasional yang berhubungan pelayanan Bank dan kepuasan konsumen.

\section{Teknik Analisis Data}

Teknik analisis yang digunakan untuk menguji data dengan uji validitas, uji reliabilitas, uji normalitas. Kemudian data diuji dengan uji t untuk melihat ada tidaknya pengaruh variabel dan uji koefisien determinan untuk mengetahui seberapa besar pengaruh variabel $\mathrm{X}$ terhadap variabel $\mathrm{Y}$

\section{HASIL DAN PEMBAHASAN Uji Validitas}

Uji validitas pada service recovery dianggap valid jika memiliki taraf signifikan di atas 5\%. Dari hasil pengolahan SPSS diperoleh uji validitas untuk variabel servis recovery pada tabel 3.1 berikut:.

Tabel 3.1 Uji Validitas Servis Recovery

\begin{tabular}{|l|c|c|c|}
\hline Pernyataan & rhitung $_{\text {rTabel }}$ & $\begin{array}{c}\text { Keterangan } \\
\text { r... }\end{array}$ \\
\hline Pertanyaan 1 & 0.361 & 0.195 & Valid \\
\hline Pertanyaan 2 & 0.739 & 0.195 & Valid \\
\hline Pertanyaan 3 & 0.698 & 0.195 & Valid \\
\hline Pertanyaan 4 & 0.548 & 0.195 & Valid \\
\hline Pertanyaan 5 & 0.301 & 0.195 & Valid \\
\hline
\end{tabular}


DOI 10.37600/ekbi.v4i1.249

\begin{tabular}{|l|l|l|l|} 
Pertanyaan 6 & 0.363 & 0.195 & Valid \\
\hline
\end{tabular}

Sumber: Olahan Data Primer

Dari tabel 3.1 hasil pengolahan data dapat dilihat bahwa uji validitas dari semua item pertanyaan 1 sampai pertanyaan 6 service recovery memiliki nilai di atas $r$-tabel 0.195. Sehingga dapat disimpulkan bahwa semua item pertanyaan dianggap valid dan dapat digunakan.

Tabel 3.2 Uji Validitas Kepuasan Nasabah

\begin{tabular}{|c|c|c|c|}
\hline Pernyataan & r $_{\text {hitung }}$ & r Tabel & $\begin{array}{c}\text { Keterangan } \\
\text { Valid }\end{array}$ \\
\hline Pertanyaan 7 & 0.694 & 0.195 & Valid \\
\hline Pertanyaan 8 & 0.700 & 0.195 & Valid \\
\hline Pertanyaan 9 & 0.656 & 0.195 & Valid \\
\hline Pertanyaan 10 & 0.690 & 0.195 & Valid \\
\hline Pertanyaan 11 & 0.687 & 0.195 & Valid \\
\hline Pertanyaan 12 & 0.330 & 0.195 & Valid \\
\hline
\end{tabular}

Sumber: Olahan Data Primer

Dari tabel 3.2 hasil pengolahan data dapat dilihat bahwa uji validitas untuk semua item pertanyaan 1 sampai 6 kepuasan nasabah memiliki nilai di atas r-tabel 0.195 maka semua item pertanyaan dianggap Valid dan dapat digunakan.

\section{Uji Reliabilitas}

Uji reliabilitas pada kepuasan nasabah dianggap reliable jika nilai dari cronbach's alpha > 0.6 dimana hasil Cronbach's Alpha yang diperoleh bahwa uji reliabilitas dari Services Recovery di atas 0.6 artinya semua item pertanyaan untuk variabel Services Recovery dianggap reliable dan untuk Uji reliabilitas Kepuasan Nasabah dimana nilai Cronbach's Alpha yang diperoleh di atas dari 0.6 sehingga semua item dari variabel kepuasan nasabah dianggap reliabel.

\section{Uji Normalitas}

Uji normalitas bertujuan untuk melihat distribusi data bersifat normal. Alat yang digunakan untuk menguji data dengan uji skewness dan kurtosis. Dimana jika nilai signifikansi lebih kecil dari 2 dan -2 maka data dianggap normal atau sebaliknya jika data lebih besar dari 0.05 maka data tidak berdistribusi normal.

Tabel 3.3 Uji Skewness dan Kurtosis variabel $\mathrm{Y}$

\begin{tabular}{|c|c|c|c|c|c|c|}
\hline \multicolumn{7}{|c|}{ Descriptive Statistics } \\
\hline & $\mathrm{N}$ & $\begin{array}{l}\text { Std. } \\
\text { Deviati } \\
\text { on }\end{array}$ & Skew & ess & Kurtc & \\
\hline & $\begin{array}{l}\text { Statist } \\
\text { ic }\end{array}$ & $\begin{array}{c}\text { Statisti } \\
\mathrm{c} \\
\end{array}$ & $\begin{array}{l}\text { Statist } \\
\text { ic }\end{array}$ & $\begin{array}{l}\text { Std. } \\
\text { Err } \\
\text { or }\end{array}$ & $\begin{array}{l}\text { Statist } \\
\text { ic }\end{array}$ & $\begin{array}{l}\text { Std. } \\
\text { Err } \\
\text { or }\end{array}$ \\
\hline Y & 97 & 2.695 & .339 & $\begin{array}{r}.24 \\
5\end{array}$ & .641 & $\begin{array}{r}.48 \\
5\end{array}$ \\
\hline $\begin{array}{l}\text { Valid N } \\
\text { (listwis } \\
\text { e) }\end{array}$ & 97 & & & & & \\
\hline
\end{tabular}

Dengan memperhatikan Statistic dan Standar eror dimana data diperoleh bahwa Skewness data $\mathrm{Y}$ adalah 0.39 dan 0.245 dan Kurtosis data statistik 0.641 dan 0.48 lebih kecil dari 2 dan -2 sehingga Variabel $\mathrm{Y}$ dinyatakan berdistribusi normal.

Tabel 3.4 Uji Skewness dan Kurtosis variabel $\mathrm{X}$

\begin{tabular}{lc|c|c|c|c|c|}
\multicolumn{9}{c|}{$\begin{array}{c}\text { Descriptive Statistics } \\
\end{array}$} & $\mathrm{N}$ & $\begin{array}{c}\text { Std. } \\
\text { Deviat } \\
\text { ion }\end{array}$ & \multicolumn{2}{c|}{ Skewness } & \multicolumn{2}{c}{ Kurtosis } \\
& $\begin{array}{c}\text { Statis } \\
\text { tic }\end{array}$ & $\begin{array}{c}\text { Statisti } \\
\mathrm{c}\end{array}$ & $\begin{array}{c}\text { Statis } \\
\text { tic }\end{array}$ & $\begin{array}{c}\text { Std. } \\
\text { Err } \\
\text { or }\end{array}$ & $\begin{array}{c}\text { Statis } \\
\text { tic }\end{array}$ & $\begin{array}{c}\text { Std. } \\
\text { Err } \\
\text { or }\end{array}$ \\
\hline $\mathrm{X}$ & 97 & 2.154 & 0.253 & 0.2 & 0.701 & 0.4 \\
\hline $\begin{array}{l}\text { Valid } \\
\text { N } \\
\text { (listwi } \\
\text { se) }\end{array}$ & 97 & & & & & \\
\hline
\end{tabular}

Dengan memperhatikan Statistic dan

Standar eror dimana data diperoleh bahwa Skewness data $\mathrm{X}$ adalah 0.253 dan 0.245 dan Kurtosis data statistik 0.7 dan 0.48 lebih kecil dari 2 dan -2 sehingga Variabel $\mathrm{X}$ dinyatakan berdistribusi normal.

\section{Koefisien Determinasi}


Uji koefisien determinasi digunakan untuk mengetahui besarnya pengaruh variabel service recovery terhadap variabel kepuasan nasabah di Bank Panin KCU Pematangsiantar dimana hasil yang diperoleh

Tabel 3.5 Koefisien Determinasi

\begin{tabular}{|c|c|c|c|c|}
\hline \multicolumn{5}{|c|}{ Model Summary ${ }^{b}$} \\
\hline Model & $\mathrm{R}$ & $\begin{array}{c}\mathrm{R} \\
\text { Square }\end{array}$ & $\begin{array}{l}\text { Adjusted } \\
\text { R Square }\end{array}$ & $\begin{array}{c}\text { Std. Error } \\
\text { of the } \\
\text { Estimate }\end{array}$ \\
\hline 1 & $.764^{a}$ & .583 & .579 & 1.750 \\
\hline
\end{tabular}

a. Predictors: (Constant), $X$

b. Dependent Variable: $Y$

Sumber: Olahan Data Primer

Dari tabel 3.5 di atas dapat disimpulkan bahwa nilai Rsquare sebesar 0.583 atau $58.3 \%$. Nilai ini diartikan bahwa terhadap pengaruh variabel $X$ service recovery terhadap kepuasan nasabah di Bank Panin KCU Pematangsiantar sebesar 58.3\% sedangkan sisanya sebesar $41.7 \%$ dipengaruhi faktor lain yang tidak diteliti dalam penelitian ini.

\section{Uji Hipotesis}

Uji t bertujuan untuk mengetahui ada atau tidak pengaruh variabel service recovery terhadap kepuasan nasabah. Pengujian ini dilakukan jika signifikan pengujian $>0.05$ maka Ho diterima dan $\mathrm{H} 1$ ditolak dan sebaliknya jika signifikan pengujian $<0.05$ maka ho ditolak dan $\mathrm{H} 1$ diterima

\section{Tabel 3.6 Uji Regresi}

\begin{tabular}{|c|c|c|c|c|c|}
\hline \multicolumn{6}{|c|}{ Coefficients $^{a}$} \\
\hline & \multicolumn{2}{|c|}{$\begin{array}{l}\text { Unstandardi } \\
\text { zed } \\
\text { Coefficients }\end{array}$} & $\begin{array}{l}\text { Standardi } \\
\text { zed } \\
\text { Coefficient } \\
\text { S }\end{array}$ & & \\
\hline Model & $\mathrm{B}$ & $\begin{array}{l}\text { Std. } \\
\text { Error }\end{array}$ & Beta & $\mathrm{t}$ & Sig \\
\hline 1 (Consta & 1.42 & 1.86 & & .763 & .44 \\
\hline & 4 & 6 & & & 7 \\
\hline$x$ & .955 & .083 & .764 & 11.5 & .00 \\
\hline & & & & 25 & 0 \\
\hline
\end{tabular}

a. Dependent Variable: $Y$
Sumber: Olahan Data Primer

Dari data tabel 3.6 di atas diketahui bahwa nilai $\mathrm{t}$ hitung sebesar 11.525 lebih besar dibanding dengan nilai t tabel 1.661 dan nilai signifikan hitung $0.000<$ dari nilai signifikan 0.005 sehingga dapat disimpulkan bahwa terdapat pengaruh positif yang signifikan antara service recovery terhadap kepuasan nasabah pada Bank Panin Cabang Pematangsiantar penelitian ini didukung dengan penelitian-penelitian terdahulu dimana dijelaskan adanya pengaruh positif signifikan antara service recovery terhadap kepuasan konsumen [4]-[6], [9], [14], [15].

Oleh karena itu pentingnya peningkatan service recovery sehingga memberikan kepastian kepada nasabah untuk mendapatkan pelayanan penanganan keluhan yang baik, mendapatkan solusi yang cepat dan tepat, memberikan prosedur pelayanan keluhan yang jelas sehingga pelangan tidak kecewa dan tetap menggunakan jasa perusahaan di masa yang akan datang.

\section{KESIMPULAN \\ Kesimpulan}

Penelitian di atas dapat disimpulkan bahwa terhadap pengaruh positif yang signifikan antara service recovery terhadap kepuasan nasabah pada Bank Panin Cabang Pematangsiantar hal ini ditunjukkan dari hasil uji regresi dimana nilai $t$ hitung sebesar 11.525 lebih besar dibanding dengan nilai $t$ tabel 1.661 dan nilai signifikan hitung $0.000<$ dari nilai signifikan 0.005 .

Besarnya pengaruh variabel service recovery terhadap kepuasan nasabah di Bank Panin KCU Pematangsiantar sebesar 58.3\% sedangkan sisanya sebesar $41.7 \%$ dipengaruhi faktor lain yang tidak diteliti dalam penelitian ini.

\section{Saran}

Penelitian ini sangat penting dalam peningkatan pelayanan Bank, khususnya ketika Bank mengalami kesalahan dalam melakukan pelayanan. Untuk mengurangi tingkat kesalahan pelayanan maka manajemen Bank perlu memperhatikan faktor-faktor service recovery disamping itu juga manajemen Bank diharapkan melakukan 
training kepada karyawan agar mampu memberikan pelayanan yang maksimal dan pelayanan recovery jika terjadi kesalahan. Bank juga perlu membuat standar prosedur pelayanan yang baik dan mudah dipahami sehingga seluruh karyawan dapat mengikuti aturan yang ditetapkan perusahaan.

Manajemen service recovery sangat penting dilakukan untuk memulihkan kekecewaan pelanggan, mempertahankan pelanggan dan menjaga citra perusahaan. Untuk penelitian berikutnya variabel yang tidak diteliti dalam penelitian ini dapat dikembangkan seperti kualitas jasa, costumer relationship management

\section{REFEREENSI}

[1] F. Halim et al., Manajemen Pemasaran Jasa. Medan: Yayasan Kita Menulis, 2021.

[2] A. Wirapraja et al., Manajemen Pemasaran Perusahaan. Medan: Yayasan Kita Menulis, 2021.

[3] H. S. Sahir et al., Dasar-Dasar Pemasaran. Medan: Yayasan Kita Menulis, 2021.

[4] S. Nursyamsiah and O. dian Virgostin, "Pengaruh Service Recovery Terhadap Loyalitas Yang Dimediasi Kepuasan Pelanggan," Ef. J. Bisnis dan Ekon., vol. 2, no. 2, pp. 136-147, 2011.

[5] N. D. Saputra and S. Sunarti, "Pengaruh Service Recovery Terhadap Kepuasan Pelanggan ( Survei pada Pelanggan PDAM Kota Malang )," $J$. Adm. Bisnis, vol. 78, no. 1, pp. 150 155, 2020.

[6] Y. Liestyana, "Persepsi Nasabah Tentang Layanan Perbankan: Pengaruh Service Failure dan Strategi Service Recovery Terhadap Behavioral Intention," J. Keuang. dan PerBank., vol. 13, no. 1, pp. 165-175, 2009.
[7] H. M. P. Simarmata, Y. Saragih, Doris, and N. J. Panjaitan, "Peningkatan Kualitas Layanan untuk Kepuasan Pelanggan Hotel," J. EK BI Politek., vol. 1, no. 1, pp. 43-51, 2018, doi: 10.31227/osf.io/54xru.

[8] R. S. Saragih and H. M. P. Simarmata, "Kepemimpinan, Kepuasan Kerja dan Motivasi terhadap Kinerja Pegawai," J. Ilm. Manaj. dan Bisnis, vol. 19, no. 2, pp. 124-133, 2019, doi: 10.30596/jimb.v19i2.2146.

[9] E. Tjitrokusumo, S. Susiani, M. Kristanti, and A. Nugroho, "Analisis Pengaruh Service Recovery Terhadap Kepuasan Konsumen," J. Hosp. dan Manaj. Jasa, vol. 2, no. 2, pp. 76-90, 2014.

[10] H. M. P. Simarmata, P. P. Simarmata, and D. Y. Saragih, "Pengaruh Lingkungan Kerja Dan Motivasi Terhadap Kinerja Aparatur Sipil Negara Di Lingkungan Kantor Walikota Pematangsiantar," J. EK\&BI, vol. 1, no. 2, pp. 69-75, 2018.

[11] R. S. Saragih and N. F. Siagian, "Pengaruh Karakteristik Individu Dan Etos Kerja Terhadap Kinerja Pegawai Pada Sekretariat Daerah Kabupaten Simalungun," J. Ekon. dan Bisnis, vol. 3, no. 1, p. 268, 2020, doi: 10.37600/ekbi.v3i1.122.

[12] H. M. P. Simarmata, "Pengaruh Kualitas Jasa, Citra Perusahaan dan Tingkat Suku Bunga Terhadap Keputusan Pengambilan Kredit Mikro," Murni Sadar, vol. 7, no. 1, pp. 16-31, 2017.

[13] P. P. Simarmata, H. M. P. Simarmata, and D. Y. Saragih, "Kualitas Pelayanan Kantor Kecamatan Terhadap Kepuasan Masyarakat Dolok Batu Nanggar Di Kabupaten Simalungun," J. Ekon. dan Bisnis, vol. 3, no. 1, pp. 241-247, 2020, doi: 
10.37600/ekbi.v3i1.119.

[14] S. 'Aliyatul Himmah, "Pengaruh Service Recovery terhadap Loyalitas Konsumen Melalui Kepuasan Konsumen Sebagai Variabel Intervening," J. Ilmu Manaj., vol. 4, no. 2, pp. 210-222, 2019, doi: 10.33474/manajemen.v4i2.3888.

[15] R. Tabita and L. M. C. Setiawan, "Analisa Pengaruh Service Recovery Terhadap Loyalitas Konsumen Melalui Kepuasan Konsumen Lion Air," $J$. Hosp. dan Manaj., vol. 5, no. 2, pp. 251-263, 2017. 